\title{
REVIEW
}

\section{Would You Recommend Screening Colonoscopy for the Very Elderly?}

\author{
Jae Myung Cha \\ Department of Internal Medicine, Kyung Hee University Hospital at Gang Dong, Kyung Hee University School of Medicine, Seoul, Korea
}

Life expectancy in Korea has increased, and the number of screening colonoscopies in the elderly has also dramatically increased. The net benefit of colonoscopy in the very elderly ( $\geq 80$ years of age as defined by the World Health Organization) may be reduced because of the competing risk of mortality due to other diseases. Therefore, the decision to perform screening colonoscopy may be more complex in this age group. As the potential increase in life expectancy due to screening colonoscopy is significantly reduced in the very elderly, this procedure should be limited to those among the very elderly who have substantial life expectancies. Furthermore, considering the common major complications associated with colonoscopy, poor bowel preparation, and the possibility of incomplete colonoscopies in the very elderly, the performance of screening colonoscopy in the very elderly may not be an ideal recommendation. In terms of providing the greatest benefit to the most number of people, patients with the highest potential gain in terms of life expectancy, relative to the diagnostic yield, should be targeted for colonoscopy screening. This review addresses the unique considerations regarding screening colonoscopy in the very elderly and the individualized approach, which involves the weighing of the risks and benefits for each individual with consideration of their overall health status. (Intest Res 2014;12:275-280)

Key Words: Age; Colonoscopy; Colonic neoplasms; Safety; Screening

\section{INTRODUCTION}

Life expectancy has increased in Korea and in most other parts of the world, according to the World Health Organization report. ${ }^{1}$ As the incidence of colorectal cancer (CRC) increases with age, screening colonoscopy plays a major role in the detection of CRCs in the elderly ${ }^{2}$ and as such, the number of screening colonoscopies performed in the elderly has dramatically increased. ${ }^{3}$ Considering the number of colonoscopy procedures performed is increasing in Korea, the issues regarding the performance of colonoscopy in the elderly are likely to increase further. Among the elderly

Received February 7, 2014. Revised February 11, 2014.

Accepted February 11, 2014.

Correspondence to Jae Myung Cha, Department of Internal Medicine,

Kyung Hee University Hospital at Gang Dong, Kyung Hee University School

of Medicine, 892 Dongnam-ro, Gangdong-gu, Seoul 134-727, Korea. Tel:

+82-2-440-6113, Fax: +82-2-440-6295, E-mail: drcha@khu.ac.kr

Financial support: None. Conflict of interest: None. population, the very elderly ( $\geq 80$ years of age as defined by the World Health Organization) may have a more heterogeneous health status; therefore, addressing the role and potential risks of colonoscopy in this population is complex. The net benefit of screening colonoscopy in the very elderly may be reduced because of the competing risk of mortality due to other diseases. ${ }^{4}$ Therefore, understanding the balance between the risks and benefits of screening colonoscopy and thereby making more informed decisions regarding the performance of screening colonoscopy is important in this population. ${ }^{5}$ This issue is now widely debated, after publication of the recent guidelines by the US Preventative Services Task Force, which advise against routine CRC screening in individuals aged 76-85 years and against any CRC screening in individuals older than 85 years. ${ }^{6}$

The rationale for the guidelines presented by the US Preventative Services Task Force is based on the results of a study by Zauber et al. ${ }^{7}$ who reported that the life years gained with screening colonoscopy decreased minimally

๑ Copyright 2014. Korean Association for the Study of Intestinal Diseases. All rights reserved.

This is an Open Access article distributed under the terms of the Creative Commons Attribution Non-Commercial License (http://creativecommons.org/licenses/by-nc/3.0)

which permits unrestricted non-commercial use, distribution, and reproduction in any medium, provided the original work is properly cited. 
at an age of 85 years from that at an age of 75 years. In this study, authors used two modified Markov microsimulation models. However, both models were limited in that they were based on prevalence data for colorectal neoplasia acquired before 1980 to eliminate the effect of CRC screening and did not consider the heterogeneity in life expectancy. In addition, most modeling studies attempting to define the cutoff age for colonoscopy screening are based on many unrealistic assumptions. Therefore, whether clinicians should perform colonoscopy screening and when colonoscopy screening should be discontinued in the very elderly are ongoing controversial issues, and decisions in this regard seem to be based on clinical judgment, with frequent reliance on personal heuristics.

This review discusses some of the issues regarding the diagnostic yield and safety of colonoscopy in the very elderly.

\section{POTENTIAL EXTENSION IN LIFE EXPECTANCY}

The primary point for consideration in adopting screening colonoscopy in the very elderly is the potential extension of life expectancy with screening colonoscopy. ${ }^{8,9}$ The American Geriatrics Society has cautions against cancer screening for individuals with short life expectancy. ${ }^{10}$ Prospective studies of the association between CRC and life expectancy are difficult to design, and therefore, a number of modeling studies have been undertaken to answer this difficult question. Many of these studies did not report an encouraging extension in life expectancy with screening colonoscopy in the very elderly. ${ }^{7,11-13}$ Inadomi and Sonnenberg ${ }^{11}$ reported that screening colonoscopy resulted in a shorter expected lifetime in the elderly (70-74 years) than in younger patients (41 vs. 170 days). Lin et al. ${ }^{12}$ also showed that the mean extension in life expectancy was much lower in the very elderly than in young individuals ( 0.13 vs. 0.85 years). Screening colonoscopy in the very elderly resulted in only a $15 \%$ extension in life expectancy relative to the expected extension in life expectancy in younger patients. Along the same lines, Zauber et al. ${ }^{7}$ reported that the life years gained with screening colonoscopy showed a minimal reduction at an age of 85 years from that at an age of 75 years. In a life-table analysis, Maheshwari et al. ${ }^{13}$ also showed that $80 \%$ of the maximal benefit of CRC screening was achieved until the age of 82 . Although these modeling studies are based on data of life expectancy after CRC diagnosis in the general American population, they support the hypothesis that the potential extension in life expectancy may be reduced in the very elderly. A plausible explanation for this is that the very elderly are more likely to die of other natural causes before death due to CRCs. For example, the expected number of deaths due to heart disease is almost 1.6 times the number of cancer deaths in very elderly men and almost 2.3 times the number in very elderly women according to cancer statistics. ${ }^{14}$ In a longitudinal cohort study, 212 patients aged 70 years or older with a positive fecal occult blood test were followed up for 7 years. ${ }^{15}$ Nearly $50 \%$ of patients who did not undergo colonoscopy died due to causes other than CRC within 5 years. In this regard, those patients with the greatest gain in terms of life expectancy should be targeted for screening colonoscopy, ${ }^{9,10}$ and this procedure should be limited to the very elderly with substantial life expectancies.

\section{DIAGNOSTIC YIELD OF COLONOSCOPY}

As CRC is associated with aging, colonoscopy is expected to provide a higher diagnostic yield in the very elderly. However, reported diagnostic yields in this population are inconsistent. ${ }^{16,17}$ In a prospective study, colonoscopy provided a high diagnostic yield (50.9\%) in very elderly patients $(n=110)$ compared with young patients. ${ }^{16}$ In contrast, in a large retrospective study $(\mathrm{n}=1,112)$, colonoscopy was associated with a low diagnostic yield (13\%) in very elderly individuals. ${ }^{17}$ In a retrospective study in the United Kingdom, ${ }^{18} 316$ colonoscopies were performed in patients aged 85 years. In this study, colonoscopy was able to identify problems that explained patients' symptoms in $37 \%$ of cases and was able to detect CRC in $8.8 \%$ of the study population. In a retrospective study based on 922 African-American patients older than 75 years, ${ }^{19}$ significant diagnostic findings were more frequently detected in the high-risk group than in the average-risk group, but were detected in only $10 \%$ of asymptomatic individuals. In this study, the diagnostic yield for CRC was much lower in asymptomatic individuals than in high-risk patients ( $0 \%$ vs. $5.4 \%, P=0.04)$. The limitations of previous studies on diagnostic yield in the very elderly includes small sample sizes ${ }^{16}$ retrospective study designs, ${ }^{17,18}$ differing definitions of diagnostic yield, and differing indications for colonoscopy (screening vs. diagnostic). ${ }^{17,19}$ Moreover, unexpectedly, the prevalence of colorectal neoplasia peaked in the eighth decade of life and declined thereafter $(P=0.009) .{ }^{20}$ Loffeld et al. ${ }^{21}$ also showed that the percentage of patients with CRC and polyps among the very elderly increases at a slow rate compared to the increase in the percentage of the very elderly in the general population. These findings may further limit the value of colonoscopy in the very elderly population, especially in screening indications for asymptomatic cases. 
For screening colonoscopy to be beneficial in the very elderly, CRC should be detected at an early stage. Populationbased colonoscopy screening data from Germany ${ }^{22}$ showed a stage shift, reflected by an increase in less-advanced stage disease and a decrease in advanced-stage disease 6 years after the implementation of screening colonoscopy. However, this finding may be limited by the lack of a causal relationship between the observations and by a very low (2.8-3.3\%) participation rate for screening colonoscopy. Specifically, the participation rate for screening colonoscopy was only less than $1 \%$ in the very elderly population, which limits the stage shift effect of screening colonoscopy in the very elderly. In another population-based, case-control study in Germany, ${ }^{23}$ a reduced risk of CRC due to colonoscopy performed in the preceding 10 years was noted in the 652 very elderly patients as well as in the overall population, irrespective of age. Interestingly, this reduction in the risk of CRC due to preceding colonoscopy was stronger for more advanced cancer, and no major difference was noted between CRC detected by screening and that detected incidentally or on the basis of symptoms. These findings raise the question about the possible benefits of screening colonoscopy in the very elderly.

\section{SAFETY OF COLONOSCOPY}

The issue of the safety of screening colonoscopy in the very elderly is an important one. In general, endoscopic procedures are safe in elderly ( $\geq 65$ years) patients with complication rates similar to those in younger patients. ${ }^{24} \mathrm{~A}$ population-based analysis that examined Medicare claims estimated an increased perforation rate within 7 days of the procedure from 0.75 per 1,000 in patients aged 65-69 to 2.95 per 1,000 in those aged 75 and older. ${ }^{25}$ More recently, a meta-analysis of 20 studies on elderly patients undergoing colonoscopy found that the very elderly were at an increased risk of perforation (incidence rate ratio, 1.7), cardiovascular and pulmonary complications (incidence rate ratio, 1.7), and total colonoscopy complications (incidence rate ratio, 1.8). ${ }^{5}$ In this study, the very elderly had a $70 \%$ increased risk of complications compared to younger patients. Table 1 summarizes the complication rates of colonoscopy in the very elderly in studies performed during the past 10 years. ${ }^{16-18,26-32}$ The pooled complication rate of colonoscopy in the very elderly is $0-0.9 \%$. The study on the Clinical Outcomes Research Initiative National Endoscopic Database, including 85 centers and more than 530 physicians, ${ }^{30}$ assessed the occurrence of the four most serious complications requiring hospitalization (perforation, postpolypectomy syndrome, bleeding, and diverticulitis) within 30 days of colonoscopy. Among 1,147 very elderly patients, 6 patients $(0.5 \%)$ had complications directly or potentially related to colonoscopy. However, this study was limited by an overall enrollment of only $53 \%$ and the lack of follow up of all subjects for up to 30 days, possibly resulting in the underestimation of complications. In addition, cardiovascular complications, which are one of the most important complications in the very elderly

Table 1. Summary of Complications Associated With Colonoscopy in the Very Elderly ( $\geq 80 \mathrm{yr}$ ), as Reported in Studies Undertaken Over the Last 10 Years

\begin{tabular}{|c|c|c|c|c|}
\hline Study & Study design & $\begin{array}{l}\text { Colonoscopies } \\
\text { (n) }\end{array}$ & $\begin{array}{l}\text { Complications } \\
\mathrm{n}(\%)\end{array}$ & $\begin{array}{c}\text { Conclusion: "Colonoscopy in the } \\
\text { very elderly is...." }\end{array}$ \\
\hline Arora and Singh $^{16}(2004)$ & Prospective & 110 & $0(0.0)$ & Safe, effective, and highly diagnostic \\
\hline Syn et al. ${ }^{26}(2005)$ & Prospective & 247 & $1(0.4)$ & Safe and highly diagnostic \\
\hline Yoong et al..$^{18}(2005)$ & Retrospective (age $\geq 80 \mathrm{yr}$ ) & 316 & $0(0.0)$ & Safe and highly diagnostic \\
\hline Duncan et al..$^{17}(2006)$ & Retrospective, cross-sectional & 1,199 & $8(0.6)$ & Safe but not highly diagnostic \\
\hline Tsutsumi et al..$^{27}(2007)$ & Prospective, cross-sectional & 110 & $1(0.9)$ & Safe, effective, and highly diagnostic \\
\hline Zerey et al. ${ }^{31}$ (2007) & Retrospective (age $\geq 85 \mathrm{yr}$ ) & 157 & $3(1.9)$ & $\begin{array}{l}\text { Safe and highly diagnostic in cases with } \\
\text { suggestive symptoms }\end{array}$ \\
\hline Arora et al. ${ }^{28}(2009)$ & Retrospective, cohort (Medicaid) & 35,227 & $42(0.1)$ & $\begin{array}{l}\text { Associated with a low perforation risk, but an } \\
\text { increasing risk with an increase in age }\end{array}$ \\
\hline Warren et al..$^{29}$ (2009) & Retrospective, cohort (Medicare) & 10,383 & NM & $\begin{array}{l}\text { Associated with a low risk, but an increasing } \\
\text { risk with an increase in age }\end{array}$ \\
\hline Ko et al..$^{30}(2010)$ & Prospective, cohort (CORI) & 1,147 & $6(0.5)$ & Safe \\
\hline Houissa et al. ${ }^{32}$ (2011) & Retrospective (age $\geq 75 \mathrm{yr}$ ) & 231 & $0(0.0)$ & Safe, well tolerated, and highly diagnostic \\
\hline
\end{tabular}

NM, not mentioned; CORI, Clinical Outcomes Research Initiative database. 
group, were not assessed in this study.

Although many authors conclude that the colonoscopy is a safe procedure in the very elderly (Table 1), these conclusions based on the complication rate of colonoscopy in the very elderly should be interpreted with caution. Most studies included a small number of patients ${ }^{16,27}$ or a large sample of administrative data, which may frequently lack details and be less appropriate for the identification of complications. ${ }^{28,29}$ Furthermore, because colonoscopic complication rates are very low (approximately $0.1-0.5 \%),{ }^{33}$ the detection of a statistically significant difference with a statistical power of $80 \%$ would require a sample size of more than 5,000, even if there were a five-fold increase in complication rates in the very elderly compared to younger patients. ${ }^{12}$ Therefore, published studies on the risks of colonoscopy in the very elderly may be underpowered because of a small sample size. When interpreting the large variation in the complication rates of colonoscopy in the very elderly, one must consider the differences in study design (retrospective vs. prospective), definitions of complications, data characteristics (Medicare vs. clinical data), study populations (screening vs. diagnostic indications), and endoscopist specialty. As the risks of complications in the very elderly may offset the benefits of screening colonoscopy and the tolerability of complications may be considerably reduced in the very elderly, careful consideration of the risks and benefits must precede any attempt at colonoscopy in the very elderly group.

\section{BOWEL PREPARATION}

Adequate bowel preparation is essential for complete colonoscopy, and the diagnostic yield of screening colonoscopy in the very elderly may be compromised by poor bowel preparation. ${ }^{24} \mathrm{~A}$ recent review suggested that adequate bowel preparation is more difficult to achieve in the very elderly, regardless of compliance and the type of bowel preparation. ${ }^{9}$ The rate of poor bowel preparation for colonoscopy in the very elderly is reported to range widely from $3.6 \%$ to 25.9\%. ${ }^{17,27}$ Possible explanations for poorer bowel preparation in the very elderly include delayed gastrointestinal motility, a high rate of constipation, poor compliance, poor understanding of the preparation instructions, a high number of previous operations, and a high frequency of comorbid diseases. ${ }^{9}$ These factors for poor bowel preparation may decrease the completion rate in the very elderly. Variable, but low completion rates (52-95\%) were reported in the very elderly. ${ }^{9}$ A retrospective study ${ }^{17}$ in the United Kingdom, based on 316 colonoscopies in patients aged 85 years, reported a completion rate of only $69 \%$, primarily because of poor bowel preparation and severe diverticular disease. A prospective study ${ }^{34}$ comparing octogenarians and non-octogenarians also reported a significantly lower completion rate in octogenarians, mainly attributed to the quality of bowel preparation. As the importance of adequate bowel preparation in the very elderly cannot be overstated, careful consideration for adequate bowel preparation should be paid for the very elderly.

\section{THE GREATEST BENEFIT FOR THE MOST NUMBER OF INDIVIDUALS}

Critical assessment of the appropriate indications for screening colonoscopy can help optimize the usage of colonoscopic resources. Medicare data suggest that the demand for colonoscopy has increased significantly over the past few years. ${ }^{3}$ Therefore, optimal use of the limited resources for colonoscopy is warranted. In 2002, the demand for screening colonoscopy in New Hampshire for patients aged more than 50 years was approximately twice the available capacity. ${ }^{35}$ According to the National Survey of Endoscopic Capacity performed by the Center for Disease Control and Prevention in the United States, only $40 \%$ of Americans at an average risk for CRC have been screened by any method within recommended intervals. ${ }^{19}$ The researchers estimated that it could take up to 10 years to screen the unscreened population using sigmoidoscopy or colonoscopy, depending on the proportion of the available capacity that is used for CRC screening. To catch up with the increasing demand of a limited resource, education on the appropriate use of screening colonoscopy may be important. As life expectancy in the very elderly varies widely, colonoscopy screening should be recommended for those with the highest potential gain in terms of life expectancy. ${ }^{10}$

With the current health-care system and the Confucian culture in Korea, restriction of screening colonoscopy on the basis of upper age criteria may rarely be imposed. ${ }^{8}$ For example, it may not be easy for colonoscopists to refuse the request for screening colonoscopy by very elderly patients. However, such individuals may make more intelligent decisions if they are fully informed about the balance between the risks and benefits of screening colonoscopy as well as the possible alternatives (including no diagnostic work up at all). ${ }^{36}$ Colonoscopists should help the very elderly patients make the best informed decision while respecting the patient's right to the final decision. 


\section{CONCLUSIONS}

"Age is just a number" is a common line on advertisements in Korea. It is true that chronological age is not a sufficient basis for making decisions regarding colonoscopy screening in the very elderly. However, it is also true that major complications related to colonoscopy, poor bowel preparation, and incomplete colonoscopy is more common in the very elderly. In this regard, screening colonoscopy for the very elderly may not be an ideal recommendation, considering the relatively low diagnostic yield and limited life expectancy. However, decision making regarding screening colonoscopy in the very elderly may require an individualized approach, with the risks and benefits for each patient being weighed according to the overall health status.

\section{REFERENCES}

1. World Health Organization. World Health Report 2012.Geneva: WHO Press, 2012.

2. SEER Cancer Statistics Review, 1975-2010 [homepage on the Internet]. Bethesda, MD: National Cancer Institute; 2013 [updated 2013 June 14; cited 2014 Jul 22]. Available from: http:// seer.cancer.gov/csr/1975_2010/.

3. Harewood GC, Lieberman DA. Colonoscopy practice patterns since introduction of medicare coverage for average-risk screening. Clin Gastroenterol Hepatol 2004;2:72-77.

4. Kahi CJ, Azzouz F, Juliar BE, Imperiale TF. Survival of elderly persons undergoing colonoscopy: implications for colorectal cancer screening and surveillance. Gastrointest Endosc 2007;66:544-550.

5. Day LW, Kwon A, Inadomi JM, Walter LC, Somsouk M. Adverse events in older patients undergoing colonoscopy: a systematic review and meta-analysis. Gastrointest Endosc 2011;74:885896.

6. U.S. Preventive Services Task Force. Screening for colorectal cancer: U.S. Preventive Services Task Force recommendation statement. Ann Intern Med 2008;149:627-637.

7. Zauber AG, Lansdorp-Vogelaar I, Knudsen AB, Wilschut J, van Ballegooijen M, Kuntz KM. Evaluating test strategies for colorectal cancer screening: a decision analysis for the U.S. Preventive Services Task Force. Ann Intern Med 2008;149:659-669.

8. Schoen RE. Pro: should screening colonoscopy be performed on an 88-yr-old healthy patient? Am J Gastroenterol 2006; 101:1713-1715.

9. Day LW, Walter LC, Velayos F. Colorectal cancer screening and surveillance in the elderly patient. Am J Gastroenterol 2011; 106:1197-1206
10. Cooper GS. Con: screening colonoscopy in the extreme elderly is not a wise choice. Am J Gastroenterol 2006;101:1715-1717.

11. Inadomi JM, Sonnenberg A. The impact of colorectal cancer screening on life expectancy. Gastrointest Endosc 2000;51:517523.

12. Lin OS, Kozarek RA, Schembre DB, et al. Screening colonoscopy in very elderly patients: prevalence of neoplasia and estimated impact on life expectancy. JAMA 2006;295:2357-2365.

13. Maheshwari S, Patel T, Patel P. Screening for colorectal cancer in elderly persons: who should we screen and when can we stop? J Aging Health 2008;20:126-139.

14. Jemal A, Siegel R, Xu J, Ward E. Cancer statistics, 2010. CA Cancer J Clin 2010;60:277-300.

15. Kistler CE, Kirby KA, Lee D, Casadei MA, Walter LC. Long-term outcomes following positive fecal occult blood test results in older adults: benefits and burdens. Arch Intern Med 2011;171: 1344-1351.

16. Arora A, Singh P. Colonoscopy in patients 80 years of age and older is safe, with high success rate and diagnostic yield. Gastrointest Endosc 2004;60:408-413.

17. Duncan JE, Sweeney WB, Trudel JL, Madoff RD, Mellgren AF. Colonoscopy in the elderly: low risk, low yield in asymptomatic patients. Dis Colon Rectum 2006;49:646-651.

18. Yoong KK, Heymann T. Colonoscopy in the very old: why bother? Postgrad Med J 2005;81:196-197.

19. Seeff LC, Manninen DL, Dong FB, et al. Is there endoscopic capacity to provide colorectal cancer screening to the unscreened population in the United States? Gastroenterology 2004;127: 1661-1669.

20. Stevens T, Burke CA. Colonoscopy screening in the elderly: when to stop? Am J Gastroenterol 2003;98:1881-1885.

21. Loffeld RJ, Liberov B, Dekkers PE. Yearly diagnostic yield of colonoscopy in patients age 80 years or older, with a special interest in colorectal cancer. Geriatr Gerontol Int 2012;12:298303.

22. Schnoor M, Waldmann A, Eberle A, Holleczek B, Katalinic A. Colorectal cancer incidence in Germany: stage-shift 6 years after implementation of a colonoscopy screening program. Cancer Epidemiol 2012;36:417-420.

23. Brenner H, Chang-Claude J, Seiler CM, Rickert A, Hoffmeister M. Protection from colorectal cancer after colonoscopy: a population-based, case-control study. Ann Intern Med 2011;154:2230 .

24. Travis AC, Pievsky D, Saltzman JR. Endoscopy in the elderly. Am J Gastroenterol 2012;107:1495-1501.

25. Gatto NM, Frucht H, Sundararajan V, Jacobson JS, Grann VR, Neugut AI. Risk of perforation after colonoscopy and sigmoidoscopy: a population-based study. J Natl Cancer Inst 2003;95: 
230-236.

26. Syn WK, Tandon U, Ahmed MM. Colonoscopy in the very elderly is safe and worthwhile. Age Ageing 2005;34:510-513.

27. Tsutsumi S, Fukushima H, Osaki K, Kuwano H. Feasibility of colonoscopy in patients 80 years of age and older. Hepatogastroenterology 2007;54:1959-1961.

28. Arora G, Mannalithara A, Singh G, Gerson LB, Triadafilopoulos G. Risk of perforation from a colonoscopy in adults: a large population-based study. Gastrointest Endosc 2009;69:654-664.

29. Warren JL, Klabunde CN, Mariotto AB, et al. Adverse events after outpatient colonoscopy in the Medicare population. Ann Intern Med 2009;150:849-857.

30. Ko CW, Riffle S, Michaels L, et al. Serious complications within 30 days of screening and surveillance colonoscopy are uncommon. Clin Gastroenterol Hepatol 2010;8:166-173.

31. Zerey M, Paton BL, Khan PD, et al. Colonoscopy in the very el- derly: a review of 157 cases. Surg Endosc 2007;21:1806-1809.

32. Houissa F, Kchir H, Bouzaidi S, et al. Colonoscopy in elderly: feasibility, tolerance and indications: about 901 cases. Tunis Med 2011;89:848-852.

33. Nelson DB, McQuaid KR, Bond JH, Lieberman DA, Weiss DG, Johnston TK. Procedural success and complications of largescale screening colonoscopy. Gastrointest Endosc 2002;55:307314.

34. Lukens FJ, Loeb DS, Machicao VI, Achem SR, Picco MF. Colonoscopy in octogenarians: a prospective outpatient study. Am J Gastroenterol 2002;97:1722-1725.

35. Butterly L, Olenec C, Goodrich M, Carney P, Dietrich A. Colonoscopy demand and capacity in New Hampshire. Am J Prev Med 2007;32:25-31.

36. Kirsch M. Screening colonoscopy in the elderly: more reasons for refusal. Am J Gastroenterol 2007;102:457. 